\title{
Cyclosporin A inhibits 12-O-tetradecanoyl-phorbol-13-acetate- induced cutaneous inflammation in severe combined immunodeficient mice that lack functional lymphocytes
}

\author{
N.J.REYNOLDS, * J.J.VOORHEES AND G.J.FISHER \\ Department of Dermatology, University of Michigan Medical School, 1150 West Medical Center Drive, R6447 Medical Science I, \\ Ann Arbor, MI 48109-0609, U.S.A. *Department of Dermatology, University of Newcastle upon Tyne, Newcastle upon Tyne, U.K. \\ Accepted for publication 26 February 1998
}

Summary A single application of 12-O-tetradecanoyl-phorbol-13-acetate (TPA) to mouse skin results in an acute inflammatory response, with an influx of neutrophils and lymphocytes, epidermal hyperplasia and abnormal keratinocyte differentiation. This response is significantly inhibited by topical cyclosporin A (CyA). Although CyA is known to inhibit T-cell activation, the role of T cells in TPA-induced cutaneous inflammation is not well understood. In this study, we have used severe combined immunodeficient (SCID) mice, which carry a spontaneous mutation resulting in the absence of functional $\mathrm{T}$ and $\mathrm{B}$ lymphocytes, to examine whether lymphocytes are required for the TPA response in mouse skin and whether CyA inhibits the TPA response in SCID mice. A significant increase in epidermal and deep dermal inflammation was observed in both SCID and CB-17 mice $24 \mathrm{~h}$ after a single application of TPA (10 nmol) compared with vehicle $(P<0 \cdot 05, n=5-7)$. Simultaneous application of CyA $(1 \cdot 7 \mu \mathrm{mol})$ plus TPA resulted in a significant reduction in epidermal and deep inflammation at $24 \mathrm{~h}$ compared with TPA alone in SCID and CB-17 mice $(P<0 \cdot 05, n=7)$. In contrast to hairless mice, a variable increase in epidermal thickness was observed in both SCID and CB-17 mice after treatment with TPA at 24 and $72 \mathrm{~h}$, which was not significantly affected by CyA. These data indicate that TPA-induced inflammation in mouse skin does not depend on lymphocytes. In addition, the inhibition of TPA-induced epidermal and deep dermal inflammation by CyA in SCID mouse skin suggests that $\mathrm{CyA}$ exerts effects on cutaneous inflammation in mice in the absence of functioning T cells.

Systemic cyclosporin A (CyA) is an effective treatment for psoriasis ${ }^{1,2}$ as well as other inflammatory dermatoses. ${ }^{3,4}$ CyA blocks the activation and proliferation of $\mathrm{T}$ cells through inhibition of $\mathrm{T}$ cell receptor-mediated interleukin 2 (IL-2) induction. ${ }^{5}$ CyA binds to intracellular receptors, cyclophilin members of the immunophilin family. The drug-immunophilin complex binds to and inhibits the $\mathrm{Ca}^{2+}$ and calmodulin-dependent phosphatase calcineurin. ${ }^{6}$ This leads to an increase in the phosphorylation state of calcineurin substrates such as the cytoplasmic subunit of nuclear factor of activated $\mathrm{T}$ cells (NF-AT). NF-AT is a transcription factor essential for IL-2 gene transcription and, in its phosphorylated state, cannot undergo translocation to the nucleus. ${ }^{7}$ Thus, by inhibiting calcineurin, CyA blocks IL-2 production, which is required for T-cell activation.

Correspondence: Dr G.J.Fisher.

Presented in part at 'Psoriasis, from Gene to Clinic', an international congress, London, U.K., 1996.
The evidence indicates that CyA exerts effects in skin that are independent of its action on T cells. CyA induces hair growth both in vivo and in vitro, ${ }^{8,9}$ indicating a direct epidermal effect. CyA inhibits the proliferation of keratinocytes and fibroblasts in culture ${ }^{10}$ at concentrations (1$10 \mu \mathrm{g} / \mathrm{mL}$ ) that have been found in psoriatic plaques after systemic administration of CyA. However, CyA inhibits keratinocyte growth only under serum-free conditions, possibly related to higher cell-associated concentrations of lipophilic CyA. Thus, whether CyA exerts an effect on keratinocyte proliferation in vivo remains controversial. CyA also inhibits antigen presentation by murine and human Langerhans cells ${ }^{11}$ and inhibits neutrophil chemotaxis in psoriatic patients. ${ }^{12}$ Thus, although CyA exerts profound effects on lymphocytes, its precise mechanism of action in skin and in psoriatic plaques, in particular, is not completely understood.

The application of a single dose of 12-O-tetradecanoyl-phorbol-13-acetate (TPA) to mouse skin results in 

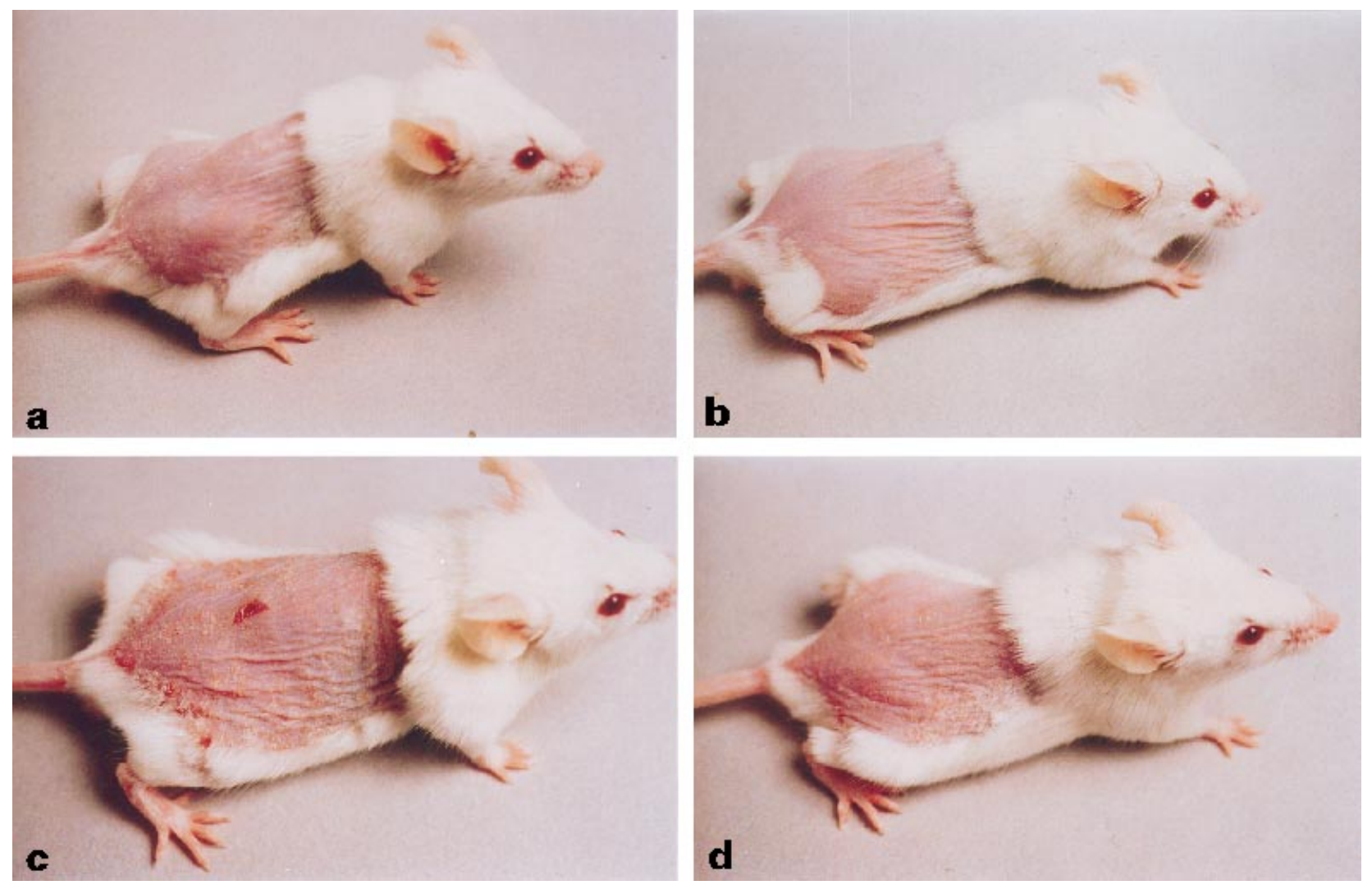

Figure 1. 12-O-tetradecanoyl-phorbol-13-acetate (TPA) induces redness and scaling in severe combined immunodeficient and CB-17 mouse skin that is inhibited by topical cyclosporin A (CyA). SCID mice (A and B) and CB-17 control mice (C and D) $72 \mathrm{~h}$ after the application of TPA (10 nmol) $(\mathrm{A}, \mathrm{C})$ and TPA $(10 \mathrm{nmol})$ plus CyA $(1 \cdot 7 \mathrm{mmol})(\mathrm{B}, \mathrm{D})$.

a wide range of responses, including epidermal hyperplasia, induction of ornithine decarboxylase (a marker of cell growth), induction of epidermal transglutaminase (a marker of terminal differentiation), alteration of keratin expression, increased release of arachidonic acid and prostaglandin (PG) $E_{2}$, increased IL- $1 \alpha$ and IL-1 $\beta$ and leucocyte infiltration. ${ }^{13-19}$ In this study, we have used severe combined immunodeficient (SCID) mice, which lack functional $\mathrm{T}$ and $\mathrm{B}$ lymphocytes but have normal monocytes, macrophages, neutrophils, megakaryocytes and erythrocytes, ${ }^{20}$ to examine directly whether functional $\mathrm{T}$ and $\mathrm{B}$ lymphocytes are necessary for the phorbol ester response in mouse skin. It was also determined whether CyA inhibits the TPA response in SCID mice, in the absence of functioning $\mathrm{T}$ and $\mathrm{B}$ lymphocytes.

\section{Materials and methods}

Mice

Homozygous CB-17/lcrTac-SCIDfDF (SCID) mice and
CB-17 control mice were purchased from Taconic (Germantown, NY, U.S.A.). Mice were derived from pathogen-free breeder stocks and were maintained in a pathogen-free animal facility at the University of Michigan in rooms vented with filtered air. Mice were housed in microisolator cages containing sterilized food and water. Investigators wore gowns, masks and sterile gloves when handling the mice.

\section{Treatment of mice and assessment of skin histology}

Experimental protocols were approved by the University of Michigan Committee on Use and Care of Animals. Mice were used for experiments at between 6 and 12 weeks of age. The backs of the mice were shaved with electric clippers and treated with a depilatory cream (Nair; Carter Products, New York, NY, U.S.A.). Only mice that displayed no evidence of hair regrowth after 3 days (i.e. hair was in the resting stage of the cycle) were used for experimentation. A single dose of TPA (Sigma Chemical Co., St Louis, MO, U.S.A.) or TPA 

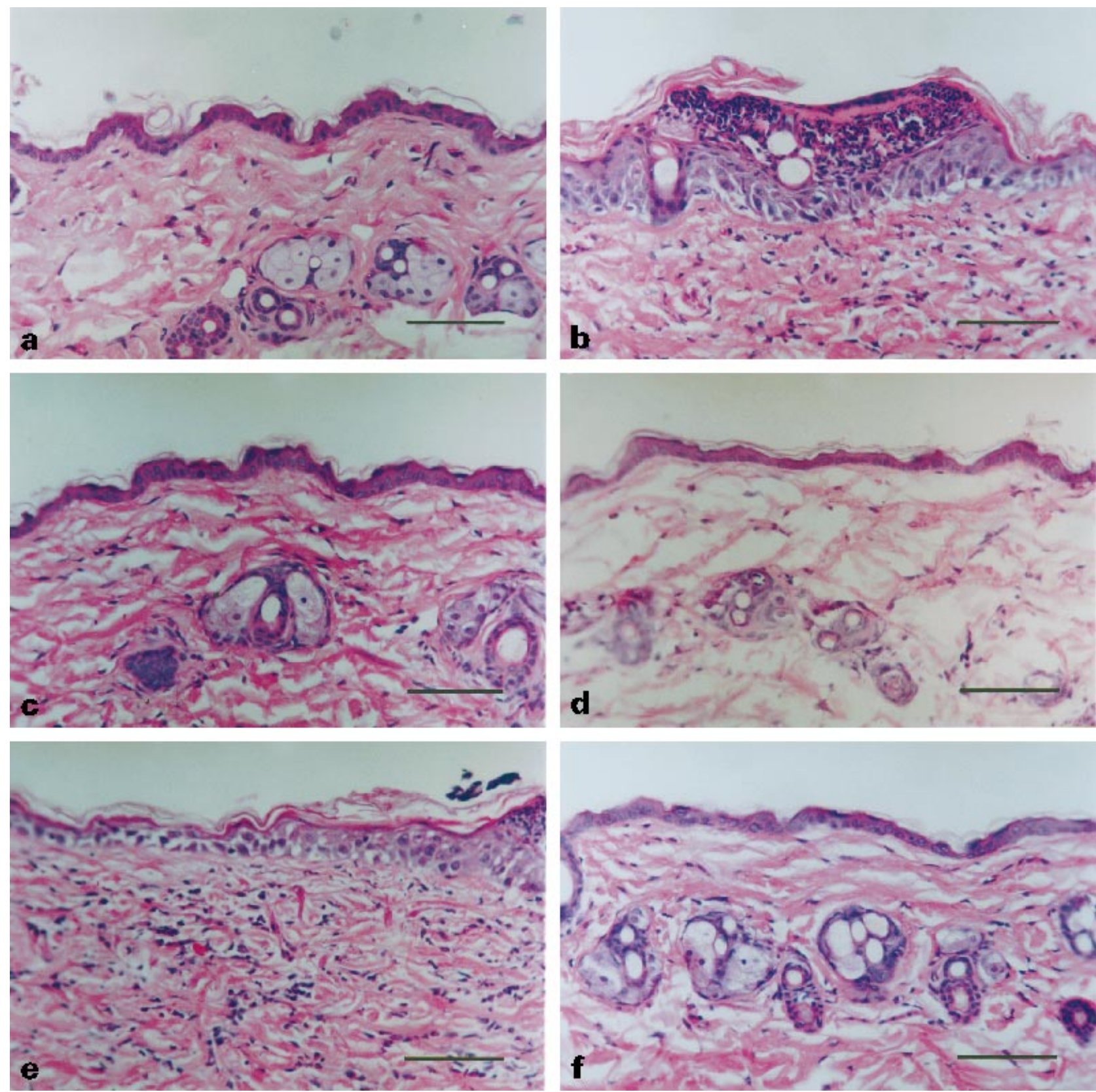

Figure 2. Topical cyclosporin A (CyA) inhibits 12-O-tetradecanoyl-phorbol-13-acetate (TPA)-induced acute epidermal and dermal inflammation in severe combined immunodeficient (SCID) and CB-17 mice. SCID mice (A-C) and CB-17 control mouse skin (D-F) were treated with vehicle (A,D), TPA $(10 \mathrm{nmol})(\mathrm{B}, \mathrm{E})$ or TPA $(10 \mathrm{nmol})$ plus CyA $(1.7 \mathrm{mmol})(\mathrm{C}, \mathrm{F})$, and biopsies were performed $24 \mathrm{~h}$ later. Scale bar $=50 \mu \mathrm{m}$.

plus CyA (a kind gift from Sandoz Pharmaceutical, Basle, Switzerland) dissolved in $200 \mu \mathrm{L}$ of acetone or vehicle was applied using a micropipette. Mice were assessed 24 or $72 \mathrm{~h}$ after treatment for erythema and scaling, and $4 \mathrm{~mm}$ punch biopsies were taken from the treated skin. Histological assessments were made by an investigator who was unaware of the treatment conditions. The degree of epidermal, upper and deep dermal inflammation was assessed using an ordinal semiquantitative five-point scale in half-unit increments, in which 0 indicated the absence of inflammation and 4 indicated the maximum degree of inflammation, as described previously. ${ }^{21}$ Epidermal thickness, measured as the distance from the bottom of the stratum corneum to 


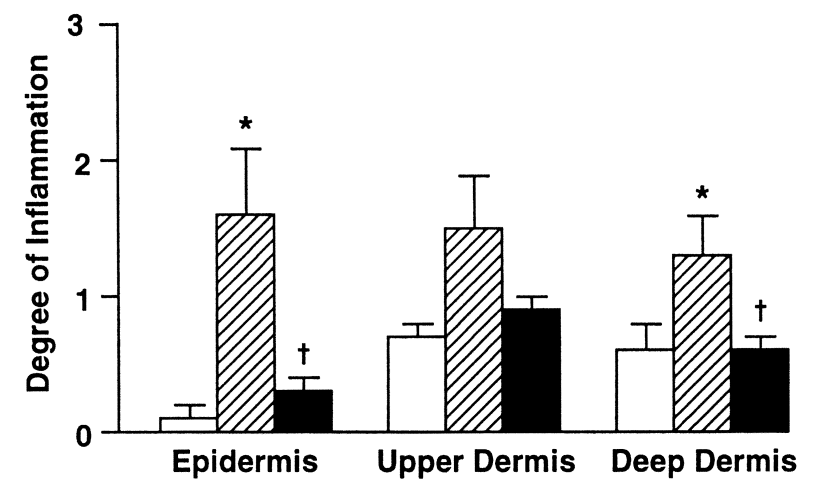

Figure 3. Inhibition of 12-O-tetradecanoyl-phorbol-13-acetate (TPA)induced epidermal and deep dermal inflammation by cyclosporin A (CyA) in severe combined immunodeficient mice. Dorsal mouse skin was treated with TPA, TPA plus CyA or vehicle, and biopsies were performed $24 \mathrm{~h}$ later. The degree of epidermal, upper dermal and deep dermal inflammation was assessed on a semiquantitative scale, as described in Materials and methods. $\square$, vehicle $(n=5)$; hatched bar, TPA, $10 \mathrm{nmol}(n=7) ; \mathbf{\square}$, TPA, $10 \mathrm{nmol}+$ CyA, $1 \cdot 7 \mathrm{mmol}(n=7)$. Data points represent mean \pm SEM. ${ }^{*} P<0.05$ vs. vehicle; $\dagger P<0.05$ vs. TPA alone.

the basement membrane in the interfollicular epidermis, was determined directly from the mean of five measurements using a calibrated micrometre scale, under light microscopy at $\times 100$ magnification.

\section{Statistical analysis}

For measurements of epidermal thickness, epidermal, upper dermal and deep dermal inflammation, comparisons

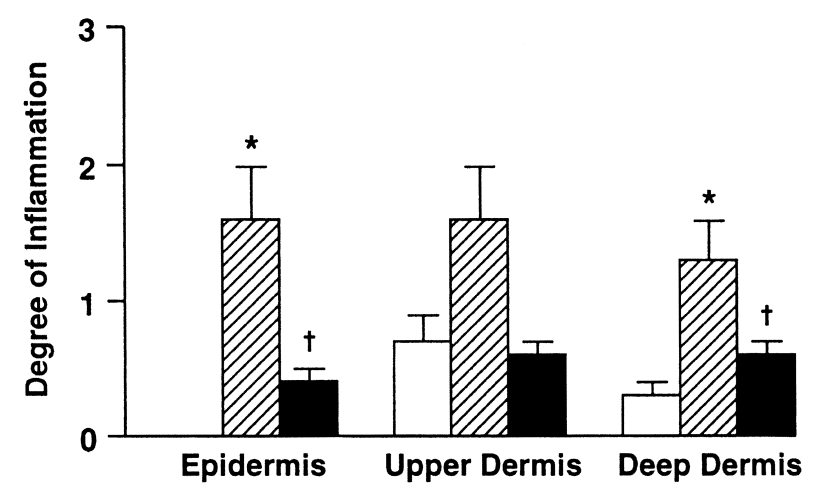

Figure 4. Inhibition of 12-O-tetradecanoyl-phorbol-13-acetate (TPA)induced epidermal and deep dermal inflammation by cyclosporin A (CyA) in CB-17 mice. Dorsal mouse skin was treated with TPA, TPA plus CyA or vehicle, and biopsies were performed $24 \mathrm{~h}$ later. The degree of epidermal, upper dermal and deep dermal inflammation was assessed on a semiquantitative scale, as described in Materials and methods. $\square$, vehicle $(n=5)$; hatched bar, TPA, $10 \mathrm{nmol}(n=7)$; TPA, $10 \mathrm{nmol}+\mathrm{CyA}, 1 \cdot 7 \mathrm{mmol}(n=7)$. Data points represent mean \pm SEM. ${ }^{*} P<0.05$ vs. vehicle; $\dagger P<0.05$ vs. TPA alone. among treatment groups were performed with one-way ANOVA and Fisher's least significant difference test.

\section{Results}

Topical treatment with TPA caused redness and scaling to similar extents in SCID and CB-17 control mouse skin at $72 \mathrm{~h}$ (Fig. 1). The degree of redness and scaling in both SCID and CB-17 mice was typically less in mice treated with TPA $(10 \mathrm{nmol})$ plus CyA $(1 \cdot 7 \mu \mathrm{mol})$ compared with TPA (10 nmol) alone (Fig. 1).

TPA (10 nmol) treatment induced an influx of inflammatory cells into the epidermis and dermis as well as spongiosis and dermal oedema $24 \mathrm{~h}$ after application in both SCID and CB-17 control mice (Fig. 2B,E). The inflammatory cells consisted predominantly of neutrophils, which formed microabscesses (Fig. 2B), and the inflammatory reaction appeared to be similar in SCID and CB-17 mice (Fig. 2B,E). Analysis of semiquantitative histological scores showed that the treatment of mouse skin with TPA resulted in a significant increase in epidermal and deep dermal inflammation in both SCID and CB17 mice $24 \mathrm{~h}$ after application $(P<0 \cdot 05, n=5-7$; Figs 3 and 4). CyA ( $1 \cdot 7 \mathrm{mmol})$, applied simultaneously with TPA (10 nmol), almost completely abrogated the TPA-induced influx of inflammatory cells into the epidermis and dermis and the TPA-induced spongiosis and dermal oedema $24 \mathrm{~h}$ after application in both SCID and CB-17 mice (Fig. 2C,F). Analysis of the semiquantitative histological scores showed that $\mathrm{CyA}$ resulted in significant reductions in epidermal and deep dermal inflammation, compared with the effects of TPA alone, at $24 \mathrm{~h}$ in SCID and CB-17 mice $(P<0 \cdot 05, n=7$, Figs 3 and 4$)$.

By $72 \mathrm{~h}$ after treatment, TPA-induced epidermal, upper dermal and deep dermal inflammation had subsided back towards control values (semiquantitative scores: $0 \cdot 8 \pm 0 \cdot 1,1 \cdot 0 \pm 0 \cdot 1$ and $0 \cdot 8 \pm 0 \cdot 1, n=8$, respectively, for SCID mice; and $0 \cdot 7 \pm 0 \cdot 2,1 \cdot 3 \pm 0 \cdot 3$ and $0 \cdot 8 \pm 0 \cdot 1$, $n=8$, respectively, for CB-17 mice). Simultaneous application of CyA and TPA resulted in no significant effect on epidermal and dermal inflammation in SCID and CB-17 mice compared with TPA alone at $72 \mathrm{~h}$.

A single application of TPA $(10 \mathrm{nmol})$ resulted in a variable increase in epidermal thickness in SCID and CB-1 7 mice at 24 and $72 \mathrm{~h}$ (Fig. 2 and Table 1). Overall, TPA induced a significant increase in epidermal thickness, compared with vehicle, only in SCID mouse skin at $24 \mathrm{~h}$ (Table 1); no significant increase in epidermal thickness in response to TPA was observed in CB-17 mice at 24 or $72 \mathrm{~h}$, compared with vehicle (Fig. 2 and Table 1). Epidermal thickness was not significantly 


\begin{tabular}{llllll}
\hline & \multicolumn{2}{l}{ Epidermal thickness $(\mu \mathrm{mol} / \mathrm{L})$} & & \\
\cline { 2 - 3 } & $24 \mathrm{~h}$ & & $72 \mathrm{~h}$ & \\
\cline { 2 - 3 } \cline { 5 - 6 } Treatment & CB-17 mice & SCID mice & & CB-17 mice & SCID mice \\
\hline $\begin{array}{llllll}\text { Vehicle } & 18 \cdot 5 \pm 1 \cdot 7^{\mathrm{a}} & 14 \cdot 1 \pm 0 \cdot 6^{\mathrm{a}} & & \mathrm{ND} & \mathrm{ND} \\
\text { TPA }(10 \mathrm{nmol}) & 24 \cdot 0 \pm 0 \cdot 8^{\mathrm{b}} & 22 \cdot 7 \pm 2 \cdot 3^{\mathrm{b} *} & & 26 \cdot 7 \pm 3 \cdot 2^{\mathrm{c}} & 25 \cdot 6 \pm 2 \cdot 0^{\mathrm{c} * *} \\
\text { TPA }(10 \mathrm{nmol}) \text { plus } & & & & & \\
\text { CyA }(1 \cdot 7 \mu \mathrm{mol})\end{array}$ & $21 \cdot 3 \pm 2 \cdot 1^{\mathrm{b}}$ & $22 \cdot 3 \pm 1 \cdot 8^{\mathrm{b}}$ & & $29 \cdot 0 \pm 4 \cdot 2^{\mathrm{c}}$ & $24 \cdot 4 \pm 4 \cdot 4^{\mathrm{c}}$ \\
\hline
\end{tabular}

Table 1 Epidermal thickness after a single treatment of dorsal SCID and CB-17 control mouse skin with 12-O-tetradecanoyl-phorbol13-acetate (TPA) and TPA plus cyclosporin A

Compounds were applied to the dorsal skin of mice as indicated, and epidermal thickness was assessed in skin biopsies taken $24 \mathrm{~h}$ or $72 \mathrm{~h}$ later, as described in Materials and methods. Data points represent mean \pm SEM for ${ }^{\mathrm{a}} n=5$ mice/group, ${ }^{\mathrm{b}} n=7$ mice/group, ${ }^{\mathrm{c}} n=8$ mice/group. ${ }^{*} P<0.05$ compared with vehicle. ${ }^{* *} P<0 \cdot 05$ compared with vehicle at $24 \mathrm{~h}\left(F_{0 \cdot 067}\right)$.

affected by simultaneous application of CyA (Fig. 2 and Table 1).

\section{Discussion}

TPA induction of epidermal, upper dermal and deep dermal inflammation to an equivalent extent in SCID and CB-17 control mice indicates that these effects are not dependent on lymphocytes. The reduction in TPAinduced epidermal and deep dermal inflammation at $24 \mathrm{~h}$ by CyA in SCID mice also indicates that CyA can exert effects on inflammatory responses in mouse skin in the absence of functioning $\mathrm{T}$ cells. These results are consistent with the previously observed ability of topical CyA to inhibit TPA-induced epidermal hyperplasia, leucocyte infiltration and keratinocyte-derived transglutaminase and ornithine decarboxylase activity in mouse skin. $^{22,23}$

The mechanisms of CyA inhibition of TPA-induced inflammation in SCID mouse skin remain to be elucidated. Even though TPA activates protein kinase $\mathrm{C}$ (PKC) in mouse skin, CyA does not block TPA-induced PKC activation or down-regulation. ${ }^{23}$ One possible mechanism is that CyA binds to cyclophilin A within keratinocytes $^{24}$ and modulates PKC signal transduction downstream of PKC activation, resulting in the inhibition of the TPA-induced release of arachidonic acid, $\mathrm{PGE}_{2}$, IL- $1 \alpha$ and IL- $1 \beta .^{23}$ Previous studies have indicated the importance of $\mathrm{PGE}_{2}$ and IL- $1 \alpha$ in the cutaneous response to TPA in mouse skin. ${ }^{16,19,25}$ The inhibition of TPA-induced, keratinocyte-derived, transglutaminase activity and ornithine decarboxylase activity by $\mathrm{CyA}^{23}$ is also consistent with CyA exerting a direct effect on epidermal keratinocytes. Alternatively, CyA may modulate the recruitment of inflammatory cells into the skin by, for example, inhibiting the ability of inflammatory cells, including neutrophils, to respond to the epidermal inflammatory signals induced by TPA or by inhibiting the induction of endothelial adhesion molecules.

Overall, epidermal hyperplasia in response to $10 \mathrm{nmol}$ of TPA appeared to be less marked in SCID and CB-17 control mice than in hairless mice. ${ }^{23}$ The reason for these differences is unknown, but different strains of mice vary in their response to TPA. ${ }^{26}$ Also, variation in the follicular response to hair removal may be relevant to the TPA response. ${ }^{27}$ Nevertheless, epidermal hyperplasia $72 \mathrm{~h}$ after the application of TPA was observed in SCID mouse skin in certain experiments, which suggests that lymphocytes may not be required for this process. In contrast to its effects in hairless mouse skin, ${ }^{23} \mathrm{CyA}$ did not significantly reduce TPA-induced epidermal hyperplasia in CB-17 control mice. This finding may have resulted from the relatively small induction of epidermal hyperplasia by TPA observed in CB-17 control mice, compared with hairless skin.

The data presented above are consistent with the concept that some of the therapeutic effects of $\mathrm{CyA}$ in inflammatory skin disease are mediated through Tcell-independent mechanisms. Thus, although the inhibition of T-cell activation by CyA is likely to be an important therapeutic mechanism of action in psoriasis, CyA may also exert direct effects on keratinocytes. Although this hypothesis requires further investigation, CyA is known to inhibit the release of inflammatory mediators from mast cells, ${ }^{28}$ and it is possible that CyA inhibits the release of keratinocyte-derived inflammatory mediators, such as arachidonic acid, prostaglandins, leukotrienes and 
cytokines, which are known to be increased in psoriatic plaques. ${ }^{29-31}$ Consistent with this hypothesis, Kojima et al. ${ }^{32}$ observed a marked reduction in GRO$\alpha$ mRNA levels within psoriatic plaques in response to CyA before detectable clinical improvement. Topical CyA is ineffective in psoriasis, probably because of inadequate absorption, as intralesional $\mathrm{CyA}$ induces local clearance. ${ }^{33}$ However, preliminary studies with FK506 suggest that topical therapy is effective in atopic eczema. ${ }^{34}$ Taken together, these studies suggest that keratinocyte immunophilins may be playing a part in the therapeutic action of CyA and FK506 in inflammatory skin disease.

\section{Acknowledgments}

We thank Ted Hamilton, MS for performing statistical analyses. This research was supported in part by the British Association of Dermatologists Dowling Travelling Fellowship (N.J.R.), the Psoriasis Association (N.J.R.) and the National Institutes of Health grant RO1-AR42419-X (G.J.F.).

\section{References}

1 Ellis CN, Gorsulowsky DC, Hamilton TA et al. Cyclosporine improves psoriasis in a double-blind study. JAMA 1986; 256: 3110-16.

2 Ellis CN, Fradin MS, Messana JM et al. Cyclosporine for plaque-type psoriasis. Results of a multidose, double-blind trial. N Engl J Med 1991; 324: 277-84.

3 Gupta AK, Ellis CN, Tellner DC et al. Cyclosporine A in the treatment of severe alopecia areata. Transplant Proc 1988; 20: 105-8.

4 Gupta AK, Ellis CN, Nickoloff BJ et al. Oral cyclosporine in the treatment of inflammatory and noninflammatory dermatoses. A clinical immunopathologic analysis. Arch Dermatol 1990; 126: 339-50.

5 Buurman WA, Ruers TJ, Daemen IA et al. Cyclosporin A inhibits IL 2-driven proliferation of human alloactivated T cells. J Immunol 1986; 136: 4035-9.

6 Liu J, Farmer JJ, Lane WS et al. Calcineurin is a common target of cyclophilin-cyclosporin A and FKBP-FK506 complexes. Cell 1991; 66: 807-15.

7 Flanagan WM, Corthesy B, Bram RJ et al. Nuclear association of a T-cell transcription factor blocked by FK-506 and cyclosporin A. Nature 1991; 352: 803-807.

8 Watanabe S, Mochizuki A, Wagatsuma K et al. Hair growth on nude mice due to cyclosporin A. J Dermatol 1991; 18: 714-19.

9 Taylor M, Ashcroft AT, Messenger AG. Cyclosporin A prolongs human hair growth in vitro. J Invest Dermatol 1993; 100: 237-9.

10 Fisher GJ, Duell EA, Nickoloff BJ et al. Levels of cyclosporin in epidermis of treated psoriasis patients differentially inhibit growth of keratinocytes cultured in serum free versus serum containing media. J Invest Dermatol 1988; 91: 142-6.

11 Furue M, Katz SI. The effect of cyclosporine on epidermal cells. I.
Cyclosporine inhibits accessory cell functions of epidermal Langerhans cells in vitro. J Immunol 1988; 140: 4139-43.

12 Pigatto PD, Pigatto LB, Bigardi A et al. Factors secreted by untreated psoriatic monocytes enhance neutrophil functions. $J$ Invest Dermatol 1990; 94: 372-6.

13 Raick AN. Ultrastructural, histological, and biochemical alterations produced by 12-O-tetradecanoyl-phorbol-13-acetate on mouse epidermis and their relevance to skin tumor promotion. Cancer Res 1973; 33: 269-86.

14 O'Brien TG, Simsiman RC, Boutwell RK. Induction of the polyamine-biosynthetic enzymes in mouse epidermis and their specificity for tumor promotion. Cancer Res 1975; 35: 2426-33.

15 Ashendel CL, Boutwell RK. Prostaglandin E and F levels in mouse epidermis are increased by tumor-promoting phorbol esters. Biochem Biophys Res Commun 1979; 90: 623-7.

16 Furstenberger G, Marks F. Indomethacin inhibition of cell proliferation induced by the phorbolester TPA is reversed by prostaglandin E2 in mouse epidermis in vivo. Biochem Biophys Res Commun 1978; 84: 1103-11.

17 Yuspa SH, Ben T, Hennings $\mathrm{H}$ et al. Phorbol ester tumor promoters induce epidermal transglutaminase activity. Biochem Biophys Res Commun 1980; 97: 700-8.

18 Molloy CJ, Laskin JD. Specific alterations in keratin biosynthesis in mouse epidermis in vivo and in explant culture following a single exposure to the tumor promoter 12-O-tetradecanoylphorbol-13acetate. Cancer Res 1987; 47: 4674-80.

19 Oberyszyn TM, Sabourin CL, Bijur GN et al. Interleukin-1 alpha gene expression and localization of interleukin-1 alpha protein during tumor promotion. Mol Carcinog 1993; 7: 238-48.

20 Bosma GC, Custer RP, Bosma MJ. A severe combined immunodeficiency mutation in the mouse. Nature 1983; 301: 527-30.

21 Fisher GJ, Esmann J, Griffiths CE et al. Cellular, immunologic and biochemical characterization of topical retinoic acid-treated human skin. J Invest Dermatol 1991; 96: 699-707.

22 Gschwendt M, Kittstein W, Marks F. Cyclosporin A inhibits phorbol ester-induced cellular proliferation and tumor promotion as well as phosphorylation of a 100-kd protein in mouse epidermis. Carcinogenesis 1987; 8: 203-7.

23 Gupta AK, Fisher GJ, Elder JT et al. Topical cyclosporine A inhibits the phorbol ester induced hyperplastic inflammatory response but not protein kinase $\mathrm{C}$ activation in mouse epidermis. J Invest Dermatol 1989; 93: 379-86.

24 Griffiths CE, Fisher GJ, Harding MW et al. Cyclophilin content of normal and psoriatic epidermis. J Invest Dermatol 1990; 94: 436-40.

25 Furstenberger G, Marks F. Early prostaglandin E synthesis is an obligatory event in the induction of cell proliferation in mouse epidermis in vivo by the phorbol ester TPA. Biochem Biophys Res Commun 1980; 92: 749-56.

26 Cope FO, Wagner FJ, Conway T et al. Tumorigenic and molecular characterization of novel phorbol ester-resistant and -sensitive lines of mice. Mol Carcinog 1988; 1: 116-24.

27 Wilson C, Cotsarelis G, Wei ZG et al. Cells within the bulge region of mouse hair follicle transiently proliferate during early anagen: heterogeneity and functional differences of various hair cycles. Differentiation 1994; 55: 127-36.

28 Triggiani M, Cirillo R, Lichtenstein LM et al. Inhibition of histamine and prostaglandin D2 release from human lung mast cells by ciclosporin A. Int Arch Allergy Appl Immunol 1989; 88: 253-5.

29 Hammarstrom S, Hamberg M, Samuelsson B et al. Increased concentrations of nonesterified arachidonic acid, 12L-hydroxy5,8,10,14-eicosatetraenoic acid, prostaglandin E2, and prostaglandin F2alpha in epidermis of psoriasis. Proc Natl Acad Sci USA 1975; 72: 5130-4. 
30 Cooper KD, Baadsgaard O, Ellis $\mathrm{CN}$ et al. Mechanisms of cyclosporine A inhibition of antigen-presenting activity in uninvolved and lesional psoriatic epidermis. J Invest Dermatol 1990; 94: 649-56.

31 Iversen L, Svendsen M, Kragballe K. Cyclosporin A down-regulates the LTB4 hydrolase level in human keratinocytes. Acta Derm Venerol (Stock) 1996; 76: 424-8.

32 Kojima T, Cromie MA, Fisher GJ et al. GRO-alpha mRNA is selectively overexpressed in psoriatic epidermis and is reduced by cyclosporin A in vivo, but not in cultured keratinocytes. J Invest Dermatol 1993; 101: 767-72.

33 Burns MK, Ellis CN, Eisen D et al. Intralesional cyclosporine for psoriasis. Relationship of dose, tissue levels, and efficacy. Arch Dermatol 1992; 128: 786-90.

34 Ruzicka T, Bieber T, Schopf E et al. A short-term trial of tacrolimus ointment for atopic dermatitis. European Tacrolimus Multicenter Atopic Dermatitis Study Group. N Engl J Med 1997; 337: 816-21. 